\title{
Design and Development of a Smart Seat for Reliefing From Pressure Ulcers
}

\author{
Dr. Shubhangi Giripunje ${ }^{1}$, Er. Rohit Tembhurne ${ }^{2}$
}

${ }^{1}$ Professor of Electronics and Telecommunication, Jhulelal Institute of Technology, Maharashtra, India

2Student of Electronics and Telecommunication, Jhulelal Institute of Technology, Maharashtra, India

\begin{abstract}
Article Info

Volume 8, Issue 3

Page Number: 276-278

Publication Issue :

May-June-2021

Article History

The long-term effects of sitting in a wheelchair can be painful. People who use wheelchairs can get muscle deformities and even serious injuries. Wheelchair injuries and pains, such as pressure ulcers, normally hit people who spend a significant amount of time in wheelchairs. Bad posture is another major challenge for people who use wheelchairs because they are not able to change their sitting position.
\end{abstract}

Accepted : 25 May 2021

Published: 31 May 2021
Keywords : Wheelchair Injuries, Fiber Bragg Grating

\section{INTRODUCTION}

A pressure ulcer is an area of skin that breaks down when something keeps pressing or rubbing against the skin. It is a localized injury to the skin and its underlying tissue, usually over a bony prominence. Older people are at high risk of developing pressure ulcers due to their decreased physical and functional health conditions, which lead to decreased mobility and confinement to chair or bed. Over $50 \%$ of pressure ulcers are around the sitting areas near to the buttocks. In the early stage, the formation of pressure ulcers can be avoided by the application of appropriate treatment and preventive measures such as special pressure relieving seat cushions.

Sitting for prolonged periods of time is thought to increase the risk of developing pressure ulcers. Sitting forces the weight of an individual against the supporting seat surface which compresses the soft tissues around the buttock area between the chair and the bony ischial tuberosities. This pressure causes an obstruction of blood flow that when combined with limited movement, poor sensation, malnutrition, and increased age can eventually lead to ulceration. These severe, yet usually preventable wounds are relatively common, spanning acute, rehabilitation, and community settings, as such, the treatment of pressure ulcers is considered to outweigh the social and financial costs associated with prevention.

One of the most effective preventative methods in terms of cost and pressure relief is regular repositioning. Within rehabilitation, individuals at risk of developing pressure ulcers are taught and encouraged to perform regular repositioning movements in order to redistribute the build-up of pressure around the ischial tuberosity and sacral regions. These repositioning movements include vertical pushups, lateral and forward leans. Occupational therapists being responsible for seating and postural care are ideally placed to educate the individual and their carers on good skin health and 
the importance of relieving pressure at the seating interface regularly.

\section{OBJECTIVES}

The objective of study was to provide a relief from the pressure ulcers to the patient and Relief the pressure of hip bones of the person on seating continuously for work.

\section{LITERATURE REVIEW}

Advanced thin-sheet force sensors are used to measure the seat pressure in real-time. Different sitting surfaces have been used to evaluate the developed pressure sensing mat. Robotic extension/retraction mechanisms are used from the base of the seat with an aim to redistribute the seat pressure on the top. The developed biomechanics has the potential to treat early stage pressure ulcers in elders. The developed seat can alleviate the problem of pressure ulcers that occur commonly in many seniors and elders especially in nursing homes[1]. Pressure ulcers are of great cost to both the patient and the healthcare system. Devices have been developed with the goal of pressure ulcer prevention, but many available technically complex devices have been shown to be no more effective than low pressure overlays or mattresses. This paper proposes a subject dependent algorithm capable of automatically detecting when and where pressure points have been relieved from underneath a supine subject, without any user inputs or assumptions[2]. In this work, a fiber Bragg grating (FBG) based sensing system for wheelchair pressure ulcer prevention was developed. Six FBGs were strategically positioned in a wheelchair to monitor the more prominent bone areas, namely scapulas (right (SR) and left (SL)), ischiatic zone (right (IR) and left (IL)), and heels (right (HR) and left (HL)). The sensing architecture was tested by a female user during pressure relief exercises, to verify its effectiveness on pressure monitoring. The proposed system proves to be a compact and reliable solution for wheelchair pressure ulcer prevention, making it a suitable alternative to existing conventional electronic sensors, with the advantage of being immune to electromagnetic interferences and usable in humid environments. In addition to the pressure, the breathing rate was also monitored. By combining the proposed sensing architecture with a wheelchair user detection software, it is possible to create alerts for the user to know when a new position should be adopted, in order to relieve the pressure in a specific area, thus avoiding one of the biggest problems for such patients, pressure ulcers.[3]

\section{APPLICATIONS}

It will be helpful in following applications:

[1] For connecting rural area patients with specialized doctors.

[2] Use By hospitals.

[3] Used For Ulcers Patient.

[4] Used For Office Employees.

\section{EXPECTED RESULT}

The proposed project design is expected to work in following ways:

[1] Relief Pressure from Creating Ulcer to patient.

[2] Relieve the seat surface pressure for different regions according to the needs of the user.

[3] The development of the seat has the potential to be used for the treatment of early stage pressure ulcer patients or elders in a nursing home environment.

\section{REFERENCES}

[1]. Catia Tavares, M. Fatima Domingues, Tiago Paixao, Nelia Alberto, Wheelchair Pressure Ulcer Prevention Using FBG Based Sensing Devices. MDPI and ACS Style 30 December 2019. 
[2]. Kwong, EWY, Hung M, and Woo K (2016). Improvement of pressure ulcer prevention care in private for-profit residential care homes: An action research study. BMC Geriatrics, 16: 192.

[3]. Alison Porter-Armstrong and may Stinson.Reviewing the Literature on the Effectiveness of Pressure Relieving Movements. Hindawi Publishing Corporation Nursing Research and practice. Article ID 124095. Published 13 Jan 2013.

[4]. Kwong EWY, Lau A, Lee R, Kwan R (2011). A pressure ulcer prevention programme specially designed for nursing homes: does it work?" Journal Clinical Nursing, 20(19-20), 2777-2786.

[5]. K. Vanderwee, M. H. F. Grypdonck, D. De Bacquer, and T. Defloor, "Effectiveness of turning with unequal time intervals on the incidence of pressure ulcer lesions," Journal of Advanced Nursing, vol. 57, no. 1, pp. 59-68, 2007.

[6]. A. Gefen, "The biomechanics of sitting-acquired pressure ulcers in patients with spinal cord injury or lesions," International Wound Journal, vol. 4, no. 3, pp. 222-236, 2007.

[7]. T. Ergic, Z. Ivandic and D. Kozak. "The Significance of Contact Pressure Distribution on The Soft Tissue by Men sitting", International Design Conference Design 2002. Dubrovnik. Croatia. May 2002.

[8]. Arduino open-source electronic prototyping platform, https://www.arduino.cc

\section{Cite this article as :}

Dr. Shubhangi Giripunje, Er. Rohit Tembhurne, "Design and Development of a Smart Seat for Reliefing From Pressure Ulcers", International Journal of Scientific Research in Science, Engineering and Technology (IJSRSET), Online ISSN : 2394-4099, Print ISSN : 2395-1990, Volume 8 Issue 3, pp. 276-278, May-June 2021. Available at doi : https://doi.org/10.32628/IJSRSET218333

Journal URL : https://ijsrset.com/IJSRSET218333 